\title{
RELAÇÕES ENTRE TRATAMENTO TÉRMICO, GERMINAÇÃO, VIGOR E SANIDADE DE SEMENTES DE TOMATE ${ }^{1}$
}

\author{
MÁRCIA PROVINZANO BRAGA²; RICARDO ALVES DE OLINDA ${ }^{3}$; \\ SÉRGIO KENJI HOMMA4; CARLOS TADEU DOS SANTOS DIAS ${ }^{5}$
}

\begin{abstract}
RESUMO - Embora o tratamento térmico apresente grande potencial no controle alternativo de patógenos de sementes, são poucos os estudos sobre essa tecnologia e, principalmente, sobre o seu efeito no desempenho das sementes, sobretudo de hortaliças. Desse modo, objetivou-se estudar a relação do tratamento térmico com o potencial fisiológico e sanidade de sementes de tomate, identificando combinações eficientes de temperatura e período de exposição por meio dos testes de sanidade e vigor. No experimento I, sementes de 2 lotes do cultivar UC-82 foram submetidas ao tratamento com água quente $\left(52,53,54,55\right.$ e $60{ }^{\circ} \mathrm{C}$ por 30 e 60 min.) e secadas por 72 horas e, juntamente com mais duas testemunhas, sementes tratadas com produto químico e sementes não tratadas, avaliadas em duas épocas pelos testes de sanidade, germinação e vigor. No experimento II, sementes tratadas com água quente a $55{ }^{\circ} \mathrm{C}$ por $30 \mathrm{~min}$. e $60{ }^{\circ} \mathrm{C}$ por $60 \mathrm{~min}$. e secadas por 12 horas, mais as mesmas testemunhas utilizadas no experimento I, foram avaliadas por meio dos testes de sanidade, germinação e vigor. Com base nos resultados, concluiu-se que o tratamento com água quente $\left(55^{\circ} \mathrm{C}\right.$ por $30 \mathrm{~min}$.) é uma opção consistente para o controle dos fungos Rhyzopus sp., Aspergillus sp. e Cladosporium sp., sem prejudicar o potencial fisiológico das sementes de tomate. Os tratamentos 52 a $54{ }^{\circ} \mathrm{C}$ por 30 ou $60 \mathrm{~min}$. não causam prejuízo ao potencial fisiológico de sementes de tomate. Os tratamentos a $60{ }^{\circ} \mathrm{C}$ por 30 ou $60 \mathrm{~min}$. são eficientes para o controle de fungos, mas letais às sementes de tomate.
\end{abstract}

Termos para indexação: tratamento de sementes; potencial fisiológico; patologia; Lycopersicon esculentum Mill.

\section{RELATIONSHIPS BETWEEN THERMAL TREATMENT, GERMINATION, VIGOR AND HEALTH OF TOMATO SEEDS}

\begin{abstract}
Thermal treatment presents great potential on the alternative control of seed pathogens. However, there are few studies on this technology and, particularly, on its effect on the performance of seeds, especially vegetable seeds. This research aimed to study the relation of thermal treatment to the physiological potential and health of tomato seeds, identifying effective combinations of temperature and exposure time by health and vigor tests. In experiment I, seeds from 2 lots of cultivar UC-82 were treated with hot water $\left(52,53,54,55\right.$ and $60{ }^{\circ} \mathrm{C}$ for 30 and $\left.60 \mathrm{~min}\right)$ and dried for 72 h. In addition to two controls (chemically treated seeds and non-treated seeds), all treatments were evaluated in two periods by health, germination and vigor tests. In experiment II, seeds treated with hot water at $55^{\circ} \mathrm{C} / 30 \mathrm{~min}$ and $60^{\circ} \mathrm{C} / 60 \mathrm{~min}$, were dried for $12 \mathrm{~h}$. These treatments, and the controls
\end{abstract}

\footnotetext{
${ }^{1}$ Submetido em 05/06/2009. Aceito para publicação em 16/10/2009.
}

Parte da Dissertação de Mestrado do primeiro autor apresentada a USP/ ESALQ.

${ }^{2}$ Eng. Agr., pós graduanda do Departamento de Produção Vegetal, USP/ ESALQ, bolsista da Fundação Mokiti Okada, agro_mpb@hotmail.com
ESALQ, Caixa Postal 9, 13418-900, Piracicaba, ricardoestatistico@usp.br

${ }^{4}$ Eng. Agr., MSc., Coordenador de Pesquisa do Centro de Pesquisa Mokiti Okada, Caixa Postal 033, 13537-000. Ipeúna, sergio.homma@cpmo.org.br

${ }^{5}$ Eng. Agr., Dr., Professor associado, Departamento de Ciências Exatas, USP/ESALQ, Caixa Postal 9, 13418-900. Piracicaba, bolsista do CNPq

${ }^{3}$ Estatístico, MSc., Doutorando do Departamento de Ciências Exatas, USP/ 
used in experiment I, were evaluated by health, germination and vigor tests. Based on the results, it was concluded that the treatment with hot water $\left(55^{\circ} \mathrm{C} / 30 \mathrm{~min}\right)$ is consistent option to control of fungi Rhyzopus sp., Aspergillus sp. and Cladosporium sp., without impairing the physiological potential of tomato seeds. The treatments 52 to $54^{\circ} \mathrm{C}$ for 30 or $60 \mathrm{~min}$ did not damage the physiological potential of tomato seeds. The treatments at $60{ }^{\circ} \mathrm{C}$ for 30 or $60 \mathrm{~min}$ are effective to control fungi, but lethal to tomato seeds.

\section{INTRODUÇÃO}

A qualidade das sementes compreende um conjunto de características que determinam seu valor para a semeadura, de modo que o potencial de desempenho das sementes somente pode ser identificado, de maneira consistente, quando é considerada a interação dos atributos de natureza genética, física, fisiológica e a sanidade (Marcos Filho, 2005).

Nesse sentido, a importância do controle de doenças transmitidas por sementes consiste, principalmente, na necessidade de se conter a transmissão a longa distância e, também, preservar a sanidade do material utilizado para multiplicação na mesma região, assim como garantir a formação de um estande uniforme. $\mathrm{O}$ emprego de agroquímicos tem sido a forma mais comum utilizada no controle de doenças; porém, verificam-se algumas desvantagens, principalmente, segundo Mendes et al.(2001), seus possíveis efeitos sobre o meio ambiente e a resistência desenvolvida pelos microrganismos a determinados compostos.

Além dos métodos químicos, o tratamento de sementes pode ser praticado utilizando-se, também, os físicos, biológicos ou a combinação entre métodos. Dentre estes, a termoterapia é um dos mais eficientes, pois possui ação erradicante de infecções profundas e não polui o meio ambiente; porém, não confere proteção residual após o tratamento, além do risco de provocar danos à semente, deteriorando mais rapidamente no período de armazenamento em comparação às não tratadas (Coutinho et al., 2007). No entanto, a falta de produtos seguros e eficientes registrados pelo Ministério da Agricultura para o tratamento de sementes de hortaliças infectadas por bactérias, e a busca por meios alternativos aos produtos químicos faz do tratamento térmico uma opção em potencial.

A termoterapia consiste na exposição do material a ser tratado à ação do calor (seco ou úmido) em combinação com o período de tratamento, visando à erradicação ou redução do patógeno. Entretanto a temperatura letal para a semente deve ser consideravelmente superior à letal para o patógeno (Machado, 2000). A termoterapia com água quente é considerada eficiente, pois a água em seu estado líquido proporciona maior condutividade de calor em relação aos demais veículos (Grondeau e Samson, 1994) e é recomendada para várias espécies de hortaliças (Neegaard, 1979), considerando-se os possíveis riscos de danos às sementes (Machado, 2000). Desse modo, para o sucesso desse sistema, faz-se necessário, o conhecimento da combinação adequada de temperatura e período de exposição, que podem variar com a espécie, cultivar, lote, vigor inicial e outros fatores.

A importância da cultura do tomateiro e o valor comercial de suas sementes justificam os esforços para ampliar as opções de tratamentos que contribuam com a qualidade de suas sementes. Embora o controle alternativo de patógenos com o tratamento térmico venha se mostrando eficiente, não são muitos os estudos sobre essa tecnologia e, principalmente, o seu efeito sobre o potencial fisiológico das sementes, sobretudo de hortaliças.

Dessa maneira, o presente trabalho objetivou estudar a relação do tratamento térmico com o potencial fisiológico e sanidade de sementes de tomate, imediatamente após o tratamento e durante o armazenamento, identificando combinações eficientes de temperatura e período de exposição através do teste de sanidade e testes de vigor.

\section{MATERIAL E MÉTODOS}

O trabalho, dividido em dois experimentos, I e II, foi realizado nos laboratórios de Análise de Sementes do Departamento de Produção Vegetal e Patologia de sementes do Departamento de Fitopatologia da USP-ESALQ, Piracicaba/SP e no Centro de Pesquisa Mokiti Okada M.O.A., Ipeúna - SP. No experimento I, sementes de dois lotes de tomate (Lycopersicon esculentum Mill.), cultivar UC-82 foram homogeneizadas e submetidas a avaliações do potencial fisiológico, grau de umidade e sanidade inicial e, em seguida, ao tratamento térmico com água quente com diferentes combinações de tempo e temperatura. Após os 
tratamentos, as sementes foram secadas por 72 horas e tiveram seus desempenhos avaliados em duas épocas, imediatamente após a secagem e após 90 dias de armazenamento. No experimento II, as sementes dos mesmos lotes iniciais foram submetidas ao tratamento térmico com duas combinações de tempo e temperatura, secadas por 12 horas e, em seguida, avaliadas quanto à sanidade e potencial fisiológico.

Nas análises preliminares dos lotes, os testes de germinação e primeira contagem de germinação foram conduzidos utilizando-se 6 repetições de 50 sementes para cada lote. As sementes foram colocadas em caixas plásticas sobre substrato de papel (mata-borrão) umedecido com quantidade de água equivalente a 2,5 vezes o peso do papel seco e mantidas a $25{ }^{\circ} \mathrm{C}$. As avaliações foram efetuadas aos 5 e 14 dias após a semeadura, contabilizando o número de plântulas normais; No teste de envelhecimento acelerado com solução saturada de $\mathrm{NaCl}$, as sementes foram envelhecidas a $41^{\circ} \mathrm{C}$ por $72 \mathrm{~h}$ (Panobianco e Marcos Filho, 2001) e, em seguida, submetidas ao teste de germinação, conforme descrito acima, com uma única contagem, aos 7 dias após a semeadura. O grau de umidade (base úmida) foi determinado pelo método da estufa a $105^{\circ} \pm 3{ }^{\circ} \mathrm{C}$ por 24 horas (Brasil, 1992), antes e após o teste de envelhecimento acelerado. O teste de sanidade (método do papel de filtro com congelamento) consistiu na incubação de 8 repetições de 25 sementes por lote a $20^{\circ} \mathrm{C} \pm 2{ }^{\circ} \mathrm{C}$, sob regime intermitente de $12 \mathrm{~h}$ de luz por $12 \mathrm{~h}$ no escuro, com congelamento (Lucca Filho, 1987). Após esse período, todas as sementes foram avaliadas para detecção e identificação de fungos.

No experimento I, os tratamentos das sementes dos lotes 1 e 2 consistiram de 10 combinações de temperatura e período de exposição (tratamento térmico) e 2 testemunhas: sementes tratadas com produto químico e sementes não tratadas. Para o tratamento térmico, $18 \mathrm{~g}$ de sementes por tratamento, em sacos de filó, foram previamente imersas em água a $40{ }^{\circ} \mathrm{C}$ por $10 \mathrm{~min}$. Em seguida, as sementes foram imediatamente transferidas para outro aparelho de banhomaria com circulação de água para serem submetidas aos 10 tratamentos compostos das combinações de temperatura (52, $53,54,55$ e $60^{\circ} \mathrm{C}$ ) e período de exposição ( 30 e 60 minutos). Antes da imersão das sementes na água quente, a temperatura requerida para cada tratamento foi previamente estabilizada e monitorada periodicamente com termômetro de precisão. Após o tempo indicado, as sementes foram resfriadas por imersão em água a temperatura ambiente e secadas por 72 horas em camadas finas sobre papel toalha, em condições de laboratório, sem controle de temperatura e umidade relativa do ar (Coutinho et al., 2007). O tratamento químico das sementes foi realizado com a aplicação do fungicida Orthocide $500 \AA$ em pó seco (dose de 1,2 g do ingrediente ativo captan por $\mathrm{kg}$ de semente).

Após os tratamentos no experimento $\mathrm{I}$, as sementes dos dois lotes foram avaliadas em duas épocas, antes e após armazenamento. As sementes destinadas às avaliações na segunda época foram colocadas em sacos de papel e armazenadas em câmara seca $\left(20^{\circ} \mathrm{C}\right.$ e $50 \%$ UR) por 90 dias. As avaliações foram feitas por meio dos testes de germinação, primeira contagem de germinação, envelhecimento acelerado com solução saturada de $\mathrm{NaCl}$ e sanidade (método do papel de filtro com congelamento), conforme descrição anterior, e emergência de plântulas em casa de vegetação, utilizando-se bandejas de poliestireno expandido de 128 células, mantidas em casa de vegetação, contendo substrato comercial Plant Bokashi ${ }^{\circledR}$, com 3 repetições de 64 sementes por tratamento. A avaliação e contagem das plântulas emergidas foram realizadas diariamente até a estabilização e o índice de velocidade de emergência de plântulas foi calculado utilizando-se fórmula proposta por Maguire (1962). O número total de plântulas normais foi computado aos 14 dias após a semeadura.

No Experimento II, os tratamentos consistiram de 2 tratamentos térmicos, imersão das sementes em água a $55^{\circ} \mathrm{C}$ por $30 \mathrm{~min}$. e $60{ }^{\circ} \mathrm{C}$ por $60 \mathrm{~min}$., e 2 testemunhas: sementes tratadas com produto químico e sementes não tratadas. Após os tratamentos com água quente, realizado conforme procedimento descrito no experimento I, as sementes tratadas dos dois lotes foram secadas por 12 horas em camadas finas sobre papel toalha, dentro de caixas plásticas cobertas com papel toalha, sem controle de ambiente. O período de secagem das sementes no experimento II foi reduzido de 72 horas para 12 horas com o intuito de diminuir a exposição das sementes ao ambiente e evitar a contaminação com microrganismos saprófitos. O tratamento químico foi realizado conforme descrito no experimento I. Após os tratamentos, em apenas uma época, as sementes foram submetidas aos testes de sanidade, germinação, primeira contagem de germinação e envelhecimento acelerado com solução saturada de $\mathrm{NaCl}$, conforme procedimentos descritos anteriormente.

Para os testes preliminares de avaliação da germinação e vigor dos lotes, a análise estatística foi realizada utilizandose o delineamento inteiramente casualizado com 2 lotes e 6 repetições de 50 sementes. Para o teste de sanidade foram utilizadas 8 repetições de 25 sementes. Após os tratamentos das sementes no experimento I, em ambas as épocas de avaliação, a análise estatística dos testes de germinação e vigor foi realizada utilizando-se o delineamento inteiramente 
casualizado em esquema fatorial 2 lotes x 12 tratamentos com 3 repetições de 50 sementes, com exceção para o teste de sanidade, realizado com 4 repetições de 25 sementes. Para os testes de emergência de plântulas, o delineamento foi em blocos ao acaso com 3 repetições de 64 sementes. Após os tratamentos das sementes no experimento II, a análise estatística dos testes de germinação e vigor foi realizada utilizando-se o delineamento inteiramente casualizado em esquema fatorial com 2 lotes $\mathrm{x} 4$ tratamentos com 3 repetições de 50 sementes e do teste de sanidade, com 4 repetições de 25 sementes. Para todos os testes, foi realizada análise de variância nos experimentos I e II e as médias comparadas pelo teste de Tukey $(\mathrm{p} \leq 0,05)$, sendo separadamente, para cada época de armazenamento, no caso do experimento I.

\section{RESULTADOS E DISCUSSÃO}

Os resultados das avaliações preliminares para caracterização dos lotes 1 e 2 do cultivar UC-82 encontramse nas tabelas 1 e 2. Na Tabela 1, são apresentados os valores médios do grau de umidade das sementes antes da instalação dos testes e após o teste de envelhecimento acelerado, assim como, dos testes de germinação e da primeira contagem de germinação e envelhecimento acelerado dos dois lotes do cultivar UC-82. A diferença no grau de umidade entre os lotes não superou 1 ponto percentual, demonstrando, segundo Marcos Filho (2005), uniformidade das amostras e consistência dos resultados apurados no teste de envelhecimento acelerado.

A análise da variância dos dados obtidos na avaliação da germinação e primeira contagem de germinação demonstrou diferença significativa entre os lotes 1 e 2 , identificando o maior potencial fisiológico do lote 1 . No teste de envelhecimento acelerado não foi confirmada a separação dos lotes em níveis de vigor.

No teste de sanidade (Tabela 2), destacou-se a incidência de Cladosporium sp. Muniz (2001) verificou, dentre outros fungos, uma incidência de 4,3\% de Cladosporium fulvum em sementes de tomate, sem danos ao potencial fisiológico, entretanto, a incidência de $7 \%$ de Cladosporium sp. observada no lote 2 , embora não tenha diferido estatisticamente do lote $1(3 \%)$, pode ter sido a causa do seu menor potencial fisiológico.

No experimento I, os valores médios obtidos na avaliação das sementes do cultivar UC-82, após os tratamentos, encontramse nas tabelas 3 e 4 . Os testes de germinação, primeira contagem de germinação e envelhecimento acelerado evidenciaram para ambos os lotes, que os tratamentos com 52 a $55^{\circ} \mathrm{C}$ por 30 ou 60 min. não afetaram o potencial fisiológico das sementes, quando comparados às testemunhas (Tabela 3 ). Resultados similares foram obtidos por McMillan (1987) em sementes de tomate.

TABELA 1. Grau de umidade inicial (GUi) e umidade após o teste de envelhecimento acelerado (GUea), germinação, primeira contagem de germinação $\left(1^{\mathrm{a} C}\right)$ e envelhecimento acelerado (EA) inicial dos lotes do cultivar de tomate UC-82.

\begin{tabular}{cccccc}
\hline \multirow{2}{*}{ Lote } & GUi & GUea & Germinação & $1{ }^{\mathrm{a} C}$ & EA \\
\cline { 2 - 6 } & \multicolumn{5}{c}{$(\%)$} \\
\hline L1 & 7,3 & 9,1 & $87 \mathrm{a}$ & $83 \mathrm{a}$ & $81 \mathrm{a}$ \\
L2 & 8,3 & 9,7 & $81 \mathrm{~b}$ & 75 & $75 \mathrm{a}$ \\
\hline & C.V. $(\%)$ & 5,3 & 6,0 & 1,9 \\
\hline
\end{tabular}

Médias seguidas pela mesma letra nas linhas não diferem significativamente entre si (Tukey, 5\%).

TABELA 2. Teste inicial de sanidade dos lotes 1 e 2 do cultivar de tomate UC-82 em incidência de fungos (\%) associados às sementes.

\begin{tabular}{ccc}
\hline Lote & Cladosporium sp. & Incidência total* $^{*}$ \\
\hline L1 & $3,0 \mathrm{a}$ & $4,0 \mathrm{a}$ \\
L2 & $7,0 \mathrm{a}$ & $8,0 \mathrm{a}$ \\
\hline C.V. $(\%)$ & 47,4 & 38,6 \\
\hline
\end{tabular}

Médias seguidas pela mesma letra nas linhas não diferem significativamente entre si (Tukey, 5\%).

*A incidência total foi composta pela soma dos fungos Cladosporium sp. a outros fungos que não foram analisados em especial em função da baixa incidência, em poucas parcelas: Aspergillus sp.; Rhizopus sp.; Penicillium sp. e Alternaria sp.

Os tratamentos com temperatura de $60{ }^{\circ} \mathrm{C}$ afetaram significativamente a viabilidade das sementes dos dois lotes (Tabela 3). Grondeau e Samson (1994) recomendaram que nos tratamentos de sementes com água quente, independentemente da espécie, a temperatura se restringisse a uma faixa de 45 a $60{ }^{\circ} \mathrm{C}$ por um período máximo de 60 minutos. Vale ressaltar, no entanto, que a sensibilidade das sementes pode variar de espécie para espécie, de cultivar para cultivar e, muitas vezes, 
de lote para lote. No tratamento de sementes de milho com água quente, Coutinho et al. (2007) também relataram a redução significativa do potencial fisiológico de sementes tratadas a 60
${ }^{\circ} \mathrm{C}$. Por outro lado, o tratamento de sementes de alfafa a $60{ }^{\circ} \mathrm{C}$ por 10, 20 ou 30 min. não acarretou prejuízo à germinação das sementes (Mendes et al., 2001).

TABELA 3. Germinação (\%), primeira contagem de germinação (\%), envelhecimento acelerado (EA) (\%), índice de velocidade de emergência de plântulas e emergência total (\%) dos lotes 1 e 2 do cultivar de tomate UC-82, após tratamento térmico no experimento $I$.

\begin{tabular}{|c|c|c|c|c|c|c|c|c|c|c|}
\hline \multirow[t]{2}{*}{ Tratamentos } & \multicolumn{2}{|c|}{ Germinação } & \multicolumn{2}{|c|}{$\begin{array}{l}\text { Primeira } \\
\text { contagem }\end{array}$} & \multicolumn{2}{|c|}{ EA } & \multicolumn{2}{|c|}{$\begin{array}{l}\text { Velocidade de } \\
\text { emergência }\end{array}$} & \multicolumn{2}{|c|}{ Emergência total } \\
\hline & Lote 1 & Lote 2 & Lote 1 & Lote 2 & Lote 1 & Lote 2 & Lote 1 & Lote 2 & Lote 1 & Lote 2 \\
\hline $\mathrm{T} 1-52{ }^{\circ} \mathrm{C} / 30 \mathrm{~min}$ & $90 \mathrm{Aa}$ & $89 \mathrm{Aa}$ & $87 \mathrm{Aa}$ & $87 \mathrm{Aa}$ & $80 \mathrm{Aa}$ & $82 \mathrm{Aa}$ & $11,4 \mathrm{ABa}$ & $9,6 \mathrm{ABb}$ & $93 \mathrm{Aa}$ & $88 \mathrm{Aa}$ \\
\hline $\mathrm{T} 2-52{ }^{\circ} \mathrm{C} / 60 \mathrm{~min}$ & $83 \mathrm{Aa}$ & $84 \mathrm{Aa}$ & $79 \mathrm{Aa}$ & $80 \mathrm{Aa}$ & $75 \mathrm{Aa}$ & $81 \mathrm{Aa}$ & $10,6 \mathrm{ABCa}$ & $9,3 \mathrm{ABb}$ & $86 \mathrm{Aa}$ & $83 \mathrm{Aa}$ \\
\hline $\mathrm{T} 3-53{ }^{\circ} \mathrm{C} / 30 \mathrm{~min}$. & $89 \mathrm{Aa}$ & $87 \mathrm{Aa}$ & $88 \mathrm{Aa}$ & $86 \mathrm{Aa}$ & $71 \mathrm{Aa}$ & $83 \mathrm{Aa}$ & $11,5 \mathrm{Aa}$ & $10,7 \mathrm{ABa}$ & $92 \mathrm{Aa}$ & $90 \mathrm{Aa}$ \\
\hline $\mathrm{T} 4-53{ }^{\circ} \mathrm{C} / 60 \mathrm{~min}$. & $79 \mathrm{Aa}$ & $86 \mathrm{Aa}$ & $75 \mathrm{Aa}$ & $82 \mathrm{Aa}$ & $77 \mathrm{Aa}$ & $81 \mathrm{Aa}$ & 9,8 $\mathrm{ABCa}$ & $9,5 \mathrm{ABa}$ & $87 \mathrm{Aa}$ & $84 \mathrm{Aa}$ \\
\hline $\mathrm{T} 5-54{ }^{\circ} \mathrm{C} / 30 \mathrm{~min}$. & $82 \mathrm{Aa}$ & $82 \mathrm{Aa}$ & $76 \mathrm{Aa}$ & $74 \mathrm{Aa}$ & $78 \mathrm{Aa}$ & $79 \mathrm{Aa}$ & $10,9 \mathrm{ABCa}$ & $11,0 \mathrm{Aa}$ & 89 Aa & $89 \mathrm{Aa}$ \\
\hline $\mathrm{T} 6-54{ }^{\circ} \mathrm{C} / 60 \mathrm{~min}$. & $84 \mathrm{Aa}$ & $82 \mathrm{Aa}$ & $78 \mathrm{Aa}$ & $78 \mathrm{Aa}$ & $85 \mathrm{Aa}$ & $81 \mathrm{Aa}$ & $9,5 \mathrm{BCa}$ & $8,9 \mathrm{Ba}$ & $83 \mathrm{Aa}$ & $79 \mathrm{Aa}$ \\
\hline $\mathrm{T} 7-55^{\circ} \mathrm{C} / 30 \mathrm{~min}$. & $83 \mathrm{Aa}$ & $83 \mathrm{Aa}$ & $79 \mathrm{Aa}$ & $80 \mathrm{Aa}$ & $73 \mathrm{Aa}$ & $76 \mathrm{Aa}$ & $10,3 \mathrm{ABCa}$ & $9,5 \mathrm{ABa}$ & $85 \mathrm{Aa}$ & $82 \mathrm{Aa}$ \\
\hline $\mathrm{T} 8-55^{\circ} \mathrm{C} / 60 \mathrm{~min}$. & $79 \mathrm{Aa}$ & $84 \mathrm{Aa}$ & $72 \mathrm{Aa}$ & $79 \mathrm{Aa}$ & $71 \mathrm{Aa}$ & $65 \mathrm{ABa}$ & $9,4 \mathrm{Ca}$ & $9,6 \mathrm{ABa}$ & $86 \mathrm{Aa}$ & $82 \mathrm{Aa}$ \\
\hline $\mathrm{T} 9-60^{\circ} \mathrm{C} / 30 \mathrm{~min}$ & $19 \mathrm{Ba}$ & $18 \mathrm{Ba}$ & $7 \mathrm{Ba}$ & $7 \mathrm{Ba}$ & $2 \mathrm{Ba}$ & $1 \mathrm{Ca}$ & $1,1 \mathrm{Da}$ & $1,5 \mathrm{Ca}$ & $18 \mathrm{Bb}$ & $24 \mathrm{Ba}$ \\
\hline $\mathrm{T} 10-60{ }^{\circ} \mathrm{C} / 60 \mathrm{~min}$. & - $0 \mathrm{Ca}$ & $0 \mathrm{Ca}$ & $0 \mathrm{Ca}$ & $0 \mathrm{Ca}$ & $0 \mathrm{Ba}$ & $0 \mathrm{Ca}$ & $0,0 \mathrm{Ea}$ & $0,0 \mathrm{Da}$ & $0 \mathrm{Ca}$ & $0 \mathrm{Ca}$ \\
\hline T11- Fungicida & $89 \mathrm{Aa}$ & $91 \mathrm{Aa}$ & $71 \mathrm{Aa}$ & $78 \mathrm{Aa}$ & $69 \mathrm{Aa}$ & $50 \mathrm{Ba}$ & $10,8 \mathrm{ABCa}$ & $10,9 \mathrm{Aa}$ & $92 \mathrm{Aa}$ & $91 \mathrm{Aa}$ \\
\hline T12- S/T & $82 \mathrm{Aa}$ & $90 \mathrm{Aa}$ & $79 \mathrm{Aa}$ & $87 \mathrm{Aa}$ & $83 \mathrm{Aa}$ & $77 \mathrm{Aa}$ & $10,0 \mathrm{ABCa}$ & $10,0 \mathrm{ABa}$ & $88 \mathrm{Aa}$ & $83 \mathrm{Aa}$ \\
\hline C.V. $(\%)$ & & 7 & & ,7 & & & $J$ & & & 2 \\
\hline
\end{tabular}

Médias seguidas pela mesma letra maiúscula nas colunas e minúscula nas linhas não diferem significativamente entre si (Tukey, 5\%).

O desempenho das sementes dos lotes 1 e 2 , avaliado por meio da emergência total de plântulas e velocidade de emergência de plântulas, confirmou os resultados dos testes de germinação e vigor (Tabela 3), identificando os tratamentos a $60{ }^{\circ} \mathrm{C}$ como os piores no tratamento das sementes dos lotes 1 e 2 do cultivar UC-82. Os resultados encontrados contradizem, em parte, os obtidos por Ikuta (1990), pois a velocidade e a porcentagem de emergência de plântulas não foram reduzidas pela exposição das sementes de tomate a 60 ${ }^{\circ} \mathrm{C}$ por $30 \mathrm{~min}$.; só houve efeito sobre o vigor das sementes quando o período de exposição foi aumentado para $60 \mathrm{~min}$. A divergência nesses resultados pode ser relacionada a diversos fatores, inclusive o genético, já que foram utilizados cultivares diferentes nos dois trabalhos.

Em especial, no lote 1, embora as sementes tratadas a $55{ }^{\circ} \mathrm{C}$ por $60 \mathrm{~min}$. não tenham diferido das testemunhas, originaram menor velocidade de emergência de plântulas que as sementes tratadas a 52 e $53{ }^{\circ} \mathrm{C}$ por 30 min., mas não diferiram das sementes tratadas às mesmas temperaturas pelo período de $60 \mathrm{~min}$. (Tabela 3 ). Desse modo, a variação na temperatura da água em $2-3{ }^{\circ} \mathrm{C}$ sobre a emergência de plântulas de tomate só ocorreu quando o período de exposição foi aumentado em $30 \mathrm{~min}$. (de 30 para $60 \mathrm{~min}$.), indicando a importância do período de exposição na combinação dos parâmetros do tratamento térmico sobre o potencial fisiológico de sementes de tomate.

Os resultados do teste de sanidade das sementes dos lotes 1 e 2 do cultivar UC-82, após os tratamentos, são apresentados na tabela 4. As sementes tratadas com água quente apresentaram incidência elevada de Cladosporium sp., inclusive, com valores médios superiores aos apresentados pelas sementes não tratadas. A provável razão para essa alta incidência do fungo pode ser atribuída à contaminação das sementes durante o período de secagem sobre a bancada 
do laboratório, às condições do ambiente, conforme recomendação da literatura (Cunha et al., 1987; Coutinho et al., 2007), até atingirem grau de umidade próximo de 10\% para melhor adequação das sementes à realização dos testes de vigor e ao período de armazenamento. Como a umidade relativa do ar manteve-se alta, variando de 80 a $90 \%$, o período de secagem se prolongou por 72 horas, o que segundo Grondeau e Samson (1994), não é recomendável, pois a secagem das sementes deve ser realizada em no máximo 1 a
2 dias para evitar a sua contaminação com microrganismos saprófitos. Assim, diante do exposto, pode-se inferir que a eliminação de microrganismos benéficos, que muitas vezes têm alto poder de antagonismo, criando um vazio microbiológico imposto pela termoterapia (Machado, 2000), aliado ao período prolongado de secagem, podem justificar a alta incidência de Cladosporium sp., não sendo possível, no experimento I, identificar relação da termoterapia com o controle dos fungos.

TABELA 4. Teste de sanidade dos lotes 1 e 2 do cultivar de tomate UC-82, em incidência de fungos (\%) associados às sementes após tratamento térmico no experimento I.

\begin{tabular}{|c|c|c|c|c|}
\hline \multirow{2}{*}{ Tratamento térmico } & \multicolumn{2}{|c|}{ Cladosporium sp. } & \multicolumn{2}{|c|}{ Incidência total* } \\
\hline & Lote 1 & Lote 2 & Lote 1 & Lote 2 \\
\hline $\mathrm{T} 1-52{ }^{\circ} \mathrm{C} / 30 \mathrm{~min}$. & $17 \mathrm{BCa}$ & $13 \mathrm{BCa}$ & $17 \mathrm{CDb}$ & $13 \mathrm{BCa}$ \\
\hline $\mathrm{T} 2-52{ }^{\circ} \mathrm{C} / 60 \mathrm{~min}$. & $15 \mathrm{BCa}$ & $28 \mathrm{Ca}$ & $15 \mathrm{BCDa}$ & $28 \mathrm{Db}$ \\
\hline $\mathrm{T} 3-53{ }^{\circ} \mathrm{C} / 30 \mathrm{~min}$. & $28 \mathrm{Ca}$ & $22 \mathrm{BCa}$ & $28 \mathrm{Db}$ & $22 \mathrm{CDa}$ \\
\hline $\mathrm{T} 4-53{ }^{\circ} \mathrm{C} / 60 \mathrm{~min}$. & $15 \mathrm{BCa}$ & $13 \mathrm{BCa}$ & $16 \mathrm{CDa}$ & $13 \mathrm{BCa}$ \\
\hline $\mathrm{T} 5-54{ }^{\circ} \mathrm{C} / 30 \mathrm{~min}$. & $21 \mathrm{BCa}$ & $23 \mathrm{Ca}$ & $21 \mathrm{CDa}$ & $23 \mathrm{CDa}$ \\
\hline $\mathrm{T} 6-54{ }^{\circ} \mathrm{C} / 60 \mathrm{~min}$. & $11 \mathrm{BCa}$ & $12 \mathrm{ABCa}$ & $11 \mathrm{BCa}$ & $14 \mathrm{BCDb}$ \\
\hline $\mathrm{T} 7-55^{\circ} \mathrm{C} / 30 \mathrm{~min}$. & $18 \mathrm{BCa}$ & $16 \mathrm{BCa}$ & $18 \mathrm{CDa}$ & $17 \mathrm{BCDa}$ \\
\hline $\mathrm{T} 8-55^{\circ} \mathrm{C} / 60 \mathrm{~min}$. & $11 \mathrm{BCa}$ & $12 \mathrm{ABCa}$ & $12 \mathrm{BCa}$ & $14 \mathrm{BCDa}$ \\
\hline $\mathrm{T} 9-60^{\circ} \mathrm{C} / 30 \mathrm{~min}$. & $13 \mathrm{BCa}$ & $15 \mathrm{BCa}$ & $13 \mathrm{BCa}$ & $15 \mathrm{BCDa}$ \\
\hline $\mathrm{T} 10-60^{\circ} \mathrm{C} / 60 \mathrm{~min}$. & $13 \mathrm{BCa}$ & $14 \mathrm{BCa}$ & $13 \mathrm{BCa}$ & $14 \mathrm{BCDa}$ \\
\hline T11- Fungicida & $0 \mathrm{Aa}$ & $0 \mathrm{Aa}$ & $0 \mathrm{Aa}$ & $0 \mathrm{Aa}$ \\
\hline T12- Sem tratamento & $6 \mathrm{ABa}$ & $6 \mathrm{ABa}$ & $5 \mathrm{Ba}$ & $8 \mathrm{Bb}$ \\
\hline C.V.(\%) & \multicolumn{2}{|c|}{26,7} & \multicolumn{2}{|c|}{23,2} \\
\hline
\end{tabular}

Médias seguidas pela mesma letra maiúscula nas colunas e minúscula nas linhas não diferem significativamente entre si (Tukey, 5\%).

*A incidência total é composta pela soma do fungo Cladosporium sp. a outros fungos que não foram analisados em especial em função da baixa incidência, em poucas parcelas: Epicoccum sp. e Alternaria sp.

No experimento I, o grau de umidade das sementes tratadas dos lotes 1 e 2 , antes dos testes de vigor, variou de 8,5 a $10,1 \%$ e após o teste de envelhecimento acelerado de 8,9 a 10,8\%. Assim, manteve-se inferior ao limite recomendado de 2 pontos percentuais, constatando, desse modo, a uniformidade das amostras e consistência dos resultados dos testes de vigor realizados na época I.

Durante o período de armazenamento (Tabela 5), as sementes dos lotes 1 e 2, no teste de germinação, velocidade e emergência de plântulas, e do lote 1 , no teste de primeira contagem de germinação, tratadas pelas combinações de 52 a $55^{\circ} \mathrm{C}$ por 30 e 60 min. não diferiram das testemunhas. Os testes de primeira contagem de germinação e envelhecimento acelerado apresentaram divergência nos resultados quanto ao vigor das sementes dos lotes 1 e 2 tratadas com água quente, durante o período de armazenamento. No entanto, o desempenho das sementes tratadas com água quente em relação às testemunhas, de ambos os lotes, avaliado por meio dos testes de velocidade e emergência de plântulas, corroborando os resultados encontrados no teste de germinação, não foi reduzido durante o período de armazenamento.

A diferença dos tratamentos realizados a $60{ }^{\circ} \mathrm{C}$ em relação às testemunhas e demais tratamentos, não foi alterada durante o período de armazenamento, conforme observado nos testes de germinação e vigor (Tabela 5). 
TABELA 5. Germinação (\%), primeira contagem de germinação (\%), envelhecimento acelerado (EA), índice de velocidade de emergência de plântulas e emergência total (\%) dos lotes 1 e 2 do cultivar de tomate UC-82, após armazenamento por 90 dias, no experimento $I$.

\begin{tabular}{|c|c|c|c|c|c|c|c|c|c|c|}
\hline \multirow[t]{2}{*}{ Tratamentos } & \multicolumn{2}{|c|}{ Germinação } & \multicolumn{2}{|c|}{ Primeira contagem } & \multicolumn{2}{|c|}{ EA } & \multicolumn{2}{|c|}{$\begin{array}{l}\text { Velocidade de } \\
\text { emergência }\end{array}$} & \multicolumn{2}{|c|}{ Emergência total } \\
\hline & Lote 1 & Lote 2 & Lote 1 & Lote 2 & Lote 1 & Lote 2 & Lote 1 & Lote 2 & Lote 1 & Lote 2 \\
\hline $\mathrm{T} 1-52{ }^{\circ} \mathrm{C} / 30 \mathrm{~min}$. & $92 \mathrm{Aa}$ & $89 \mathrm{Aa}$ & $60 \mathrm{Aa}$ & $41 \mathrm{ABb}$ & $66 \mathrm{Aa}$ & $71 \mathrm{Aa}$ & 9,8 Aa & $10,9 \mathrm{Aa}$ & $81 \mathrm{Aa}$ & $86 \mathrm{Aa}$ \\
\hline $\mathrm{T} 2-52{ }^{\circ} \mathrm{C} / 60 \mathrm{~min}$. & $90 \mathrm{Aa}$ & $90 \mathrm{Aa}$ & $50 \mathrm{Aa}$ & $41 \mathrm{ABa}$ & $63 \mathrm{ABa}$ & $71 \mathrm{Aa}$ & $10,4 \mathrm{Aa}$ & 9,8 Aa & $84 \mathrm{Aa}$ & $79 \mathrm{Aa}$ \\
\hline $\mathrm{T} 3-53^{\circ} \mathrm{C} / 30 \mathrm{~min}$. & $85 \mathrm{Aa}$ & $87 \mathrm{Aa}$ & $44 \mathrm{Aa}$ & $36 \mathrm{ABCa}$ & $69 \mathrm{Aa}$ & $63 \mathrm{ABa}$ & $10,6 \mathrm{Aa}$ & $10,5 \mathrm{Aa}$ & $87 \mathrm{Aa}$ & $83 \mathrm{Aa}$ \\
\hline $\mathrm{T} 4-53^{\circ} \mathrm{C} / 60 \mathrm{~min}$. & $85 \mathrm{Aa}$ & $85 \mathrm{Aa}$ & $45 \mathrm{Aa}$ & $41 \mathrm{ABa}$ & $49 \mathrm{ABCa}$ & $53 \mathrm{ABa}$ & $10,9 \mathrm{Aa}$ & $10,3 \mathrm{Aa}$ & $88 \mathrm{Aa}$ & $82 \mathrm{Aa}$ \\
\hline $\mathrm{T} 5-54{ }^{\circ} \mathrm{C} / 30 \mathrm{~min}$. & $89 \mathrm{Aa}$ & $83 \mathrm{Aa}$ & $50 \mathrm{Aa}$ & $20 \mathrm{BCb}$ & $69 \mathrm{Aa}$ & $69 \mathrm{Aa}$ & $11,2 \mathrm{Aa}$ & $10,5 \mathrm{Aa}$ & $89 \mathrm{Aa}$ & $85 \mathrm{Aa}$ \\
\hline $\mathrm{T} 6-54^{\circ} \mathrm{C} / 60 \mathrm{~min}$. & $84 \mathrm{Aa}$ & $84 \mathrm{Aa}$ & $48 \mathrm{Aa}$ & $49 \mathrm{Aa}$ & $42 \mathrm{Cb}$ & $67 \mathrm{ABa}$ & $10,0 \mathrm{Aa}$ & $10,3 \mathrm{Aa}$ & $86 \mathrm{Aa}$ & $82 \mathrm{Aa}$ \\
\hline $\mathrm{T} 7-55^{\circ} \mathrm{C} / 30 \mathrm{~min}$. & $85 \mathrm{Aa}$ & $89 \mathrm{Aa}$ & $51 \mathrm{Aa}$ & $43 \mathrm{ABa}$ & $63 \mathrm{ABa}$ & $58 \mathrm{ABa}$ & $10,9 \mathrm{Aa}$ & $10,5 \mathrm{Aa}$ & $87 \mathrm{Aa}$ & $85 \mathrm{Aa}$ \\
\hline $\mathrm{T} 8-55^{\circ} \mathrm{C} / 60 \mathrm{~min}$. & $75 \mathrm{Aa}$ & $85 \mathrm{Aa}$ & $35 \mathrm{Aa}$ & $42 \mathrm{ABa}$ & $45 \mathrm{BCa}$ & $49 \mathrm{Ba}$ & $10,0 \mathrm{Aa}$ & $10,0 \mathrm{Aa}$ & $81 \mathrm{Aa}$ & $81 \mathrm{Aa}$ \\
\hline $\mathrm{T} 9-60{ }^{\circ} \mathrm{C} / 30 \mathrm{~min}$. & $29 \mathrm{Ba}$ & $19 \mathrm{Ba}$ & $0 \mathrm{Ba}$ & $0 \mathrm{Da}$ & $3 \mathrm{Da}$ & $1 \mathrm{Ca}$ & $1,4 \mathrm{Ba}$ & $1,2 \mathrm{Ba}$ & $21 \mathrm{Ba}$ & $18 \mathrm{Ba}$ \\
\hline $\mathrm{T} 10-60^{\circ} \mathrm{C} / 60 \mathrm{~min}$. & $0 \mathrm{Ca}$ & $0 \mathrm{Ca}$ & $0 \mathrm{Ba}$ & $0 \mathrm{Da}$ & $0 \mathrm{Da}$ & $0 \mathrm{Ca}$ & $0,0 \mathrm{Ca}$ & $0,0 \mathrm{Ca}$ & $0 \mathrm{Ca}$ & $0 \mathrm{Ca}$ \\
\hline T11- Fungicida & $81 \mathrm{Aa}$ & $89 \mathrm{Aa}$ & $33 \mathrm{Aa}$ & $15 \mathrm{Cb}$ & $53 \mathrm{ABCa}$ & $51 \mathrm{ABa}$ & $11,4 \mathrm{Aa}$ & $10,8 \mathrm{Aa}$ & $90 \mathrm{Aa}$ & $87 \mathrm{Aa}$ \\
\hline $\mathrm{T} 12-\mathrm{S} / \mathrm{T}$ & $85 \mathrm{Aa}$ & $88 \mathrm{Aa}$ & $52 \mathrm{Aa}$ & $47 \mathrm{Aa}$ & $65 \mathrm{Aa}$ & $65 \mathrm{ABa}$ & $10,9 \mathrm{Aa}$ & $10,6 \mathrm{Aa}$ & $88 \mathrm{Aa}$ & $85 \mathrm{Aa}$ \\
\hline C.V. $(\%)$ & & & & & 7,0 & & & $\gamma$ & & 2 \\
\hline
\end{tabular}

Médias seguidas pela mesma letra maiúscula nas colunas e minúscula nas linhas não diferem significativamente entre si (Tukey, 5\%).

$* \mathrm{~S} / \mathrm{T}=$ Sem Tratamento

Os resultados do teste de sanidade realizado após o período de armazenamento encontram-se na Tabela 6. A associação de Aspergillus sp., fungo comum em armazenamento, com as sementes de alguns tratamentos, inclusive nas sementes não tratadas do lote 2 pode ter ocorrido durante o armazenamento, embora a incidência seja baixa, já que não foi constatada a presença do microrganismo após o tratamento. Com relação ao Cladosporium sp., durante o período de armazenamento, observou-se uma ligeira redução na incidência do fungo das sementes tratadas com água quente nos dois lotes do cultivar UC-82. O fato pode ser justificado pelas condições oferecidas pelo ambiente de armazenamento, com baixa temperatura e umidade relativa do ar, pois segundo Neegard (1979), o armazenamento adequado pode reduzir a viabilidade de alguns fungos. Vale destacar, inclusive, que as sementes de ambos os lotes tratadas a $55{ }^{\circ} \mathrm{C}$ por $60 \mathrm{~min}$. e a $60{ }^{\circ} \mathrm{C}$ por 30 e 60 min. e as sementes do lote 2 tratadas a $54^{\circ} \mathrm{C}$ por 60 min. apresentaram menor incidência do fungo em relação às sementes não tratadas.

O grau de umidade das sementes dos lotes 1 e 2, avaliado após o período de 90 dias de armazenamento, manteve-se inferior ao limite recomendado, variando de 6,9 a $8,7 \%$. Após o teste de envelhecimento acelerado, a variação foi de 9,1 a $10,6 \%$.

$\mathrm{Na}$ condução do segundo experimento, o teste de sanidade (Tabela 7) revelou a incidência de fungos do gênero Rhyzopus, Aspergillus e Cladosporium associados às sementes dos dois lotes do cultivar UC-82. A análise dos dados constatou controle dos fungos pelos tratamentos com água quente a 55 e $60{ }^{\circ} \mathrm{C}$ pelos períodos de 30 e $60 \mathrm{~min}$., respectivamente. Muniz (2001) não obteve êxito no controle de Cladosporium fulvum com o tratamento das sementes de tomate a $50{ }^{\circ} \mathrm{C}$ por $30 \mathrm{~min}$., indicando que o controle do gênero Cladosporium provavelmente requer temperaturas acima de $50{ }^{\circ} \mathrm{C}$. No controle de Aspergillus sp. e Rhizopus stolonifer em sementes de milho, o tratamento a $50{ }^{\circ} \mathrm{C}$ por $10 \mathrm{~min}$. foi eficaz, ainda que a $52{ }^{\circ} \mathrm{C}$ o controle tenha sido mais expressivo (Rahman et al., 2008), sugerindo maior sensibilidade dos fungos desses gêneros ao tratamento.

$\mathrm{O}$ tratamento com água aquecida a $55{ }^{\circ} \mathrm{C}$ por $30 \mathrm{~min}$. não reduziu a germinação e o vigor (primeira contagem de germinação e envelhecimento acelerado) das sementes dos 
lotes 1 e 2, quando comparado à testemunha, sementes não tratadas (Tabela 8). Quando as sementes foram tratadas a
$60{ }^{\circ} \mathrm{C}$ por 60 min., não houve germinação, inviabilizando ambos os lotes.

TABELA 6. Teste de sanidade dos lotes 1 e 2 do cultivar de tomate UC-82, em incidência de fungos (\%) associados às sementes após armazenamento por 90 dias, no experimento $I$.

\begin{tabular}{|c|c|c|c|c|c|c|}
\hline \multirow{3}{*}{ Tratamento térmico } & \multicolumn{2}{|c|}{ Aspergillus sp. } & \multicolumn{2}{|c|}{ Cladosporium sp. } & \multicolumn{2}{|c|}{ Incidência total* } \\
\hline & Lote 1 & Lote 2 & Lote 1 & Lote 2 & Lote 1 & Lote 2 \\
\hline & \multicolumn{6}{|c|}{$(\%)$} \\
\hline $\mathrm{T} 1-52{ }^{\circ} \mathrm{C} / 30 \mathrm{~min}$. & $1 \mathrm{Aa}$ & $2 \mathrm{Aa}$ & $5 \mathrm{ABa}$ & $9 \mathrm{ABCa}$ & $9 \mathrm{BCa}$ & $12 \mathrm{CDb}$ \\
\hline $\mathrm{T} 2-52{ }^{\circ} \mathrm{C} / 60 \mathrm{~min}$. & $1 \mathrm{Aa}$ & $0 \mathrm{Aa}$ & $9 \mathrm{ABa}$ & $5 \mathrm{ABCa}$ & $12 \mathrm{CDb}$ & $6 \mathrm{BCa}$ \\
\hline $\mathrm{T} 3-53{ }^{\circ} \mathrm{C} / 30 \mathrm{~min}$. & $1 \mathrm{Aa}$ & $2 \mathrm{Aa}$ & $16 \mathrm{Ba}$ & $14 \mathrm{BCa}$ & $21 \mathrm{Db}$ & $18 \mathrm{DEa}$ \\
\hline $\mathrm{T} 4-53{ }^{\circ} \mathrm{C} / 60 \mathrm{~min}$. & $0 \mathrm{Aa}$ & $0 \mathrm{Aa}$ & $15 \mathrm{Ba}$ & $8 \mathrm{ABCa}$ & $15 \mathrm{CDb}$ & $12 \mathrm{CDa}$ \\
\hline $\mathrm{T} 5-54{ }^{\circ} \mathrm{C} / 30 \mathrm{~min}$ & $0 \mathrm{Aa}$ & $2 \mathrm{Aa}$ & $15 \mathrm{Ba}$ & $8 \mathrm{ABCa}$ & $17 \mathrm{CDb}$ & $10 \mathrm{CDa}$ \\
\hline $\mathrm{T} 6-54{ }^{\circ} \mathrm{C} / 60 \mathrm{~min}$. & $1 \mathrm{Aa}$ & $0 \mathrm{Aa}$ & $8 \mathrm{ABa}$ & $3 \mathrm{Aba}$ & $9 \mathrm{BCa}$ & $7 \mathrm{BCa}$ \\
\hline $\mathrm{T} 7-55^{\circ} \mathrm{C} / 30 \mathrm{~min}$. & $3 \mathrm{Aa}$ & $1 \mathrm{Aa}$ & $16 \mathrm{Ba}$ & $9 \mathrm{ABCa}$ & $23 \mathrm{Db}$ & $12 \mathrm{CDa}$ \\
\hline $\mathrm{T} 8-55^{\circ} \mathrm{C} / 60 \mathrm{~min}$. & $1 \mathrm{Aa}$ & $0 \mathrm{Aa}$ & $0 \mathrm{Aa}$ & $2 \mathrm{Aba}$ & $2 \mathrm{Aa}$ & $2 \mathrm{ABa}$ \\
\hline $\mathrm{T} 9-60{ }^{\circ} \mathrm{C} / 30 \mathrm{~min}$. & $0 \mathrm{Aa}$ & $0 \mathrm{Aa}$ & $1 \mathrm{Aa}$ & $1 \mathrm{Aa}$ & $3 \mathrm{ABa}$ & $2 \mathrm{ABa}$ \\
\hline $\mathrm{T} 10-60{ }^{\circ} \mathrm{C} / 60 \mathrm{~min}$. & $0 \mathrm{Aa}$ & $0 \mathrm{Aa}$ & $0 \mathrm{Aa}$ & $2 \mathrm{Aba}$ & $0 \mathrm{Aa}$ & $3 \mathrm{ABb}$ \\
\hline T11- Fungicida & $0 \mathrm{Aa}$ & $0 \mathrm{Aa}$ & $0 \mathrm{Aa}$ & $0 \mathrm{Aa}$ & $0 \mathrm{Aa}$ & $0 \mathrm{Aa}$ \\
\hline T12- Sem tratamento & $0 \mathrm{Aa}$ & $6 \mathrm{Ab}$ & $18 \mathrm{Ba}$ & $16 \mathrm{Ca}$ & $22 \mathrm{Da}$ & $26 \mathrm{~Eb}$ \\
\hline C.V.(\%) & \multicolumn{2}{|r|}{44,1} & \multicolumn{2}{|r|}{35,2} & \multicolumn{2}{|c|}{25,9} \\
\hline
\end{tabular}

Médias seguidas pela mesma letra maiúscula nas colunas e minúscula nas linhas (entre lotes) não diferem significativamente entre si (Tukey, 5\%).

*A incidência total foi composta pela soma dos fungos Aspergillus sp. e Cladosporium sp. a outros fungos que não foram analisados em especial em função da baixa incidência, em poucas parcelas: Rhizopus sp.; Phoma sp.; Fusarium sp.; Drechslera sp.; Curvularia sp.; Stemphylium sp.; Epicoccum sp. e Alternaria sp.

TABELA 7. Teste de sanidade dos lotes 1 e 2 do cultivar de tomate UC-82, em incidência de fungos (\%) associados às sementes após tratamento térmico no experimento II.

\begin{tabular}{|c|c|c|c|c|c|c|c|c|}
\hline \multirow{2}{*}{ Tratamento térmico } & \multicolumn{2}{|c|}{ Rhyzopus sp. } & \multicolumn{2}{|c|}{ Aspergillus sp. } & \multicolumn{2}{|c|}{ Cladosporium sp. } & \multicolumn{2}{|c|}{ Incidência total } \\
\hline & Lote 1 & Lote 2 & Lote 1 & Lote 2 & Lote 1 & Lote 2 & Lote 1 & Lote 2 \\
\hline $\mathrm{T} 7-55^{\circ} \mathrm{C} / 30 \mathrm{~min}$ & $0 \mathrm{Aa}$ & $0 \mathrm{Aa}$ & $0 \mathrm{Aa}$ & $0 \mathrm{Aa}$ & $0 \mathrm{Aa}$ & $1,6 \mathrm{Bb}$ & $0 \mathrm{Aa}$ & $1,6 \mathrm{Bb}$ \\
\hline $\mathrm{T} 10-60^{\circ} \mathrm{C} / 60 \mathrm{~min}$. & $0 \mathrm{Aa}$ & $0 \mathrm{Aa}$ & $0 \mathrm{Aa}$ & $0 \mathrm{Aa}$ & $0 \mathrm{Aa}$ & $0 \mathrm{Aa}$ & $0 \mathrm{Aa}$ & 0 Aa \\
\hline T11-Fungicida & $0 \mathrm{Aa}$ & $0 \mathrm{Aa}$ & $0 \mathrm{Aa}$ & $0 \mathrm{Aa}$ & $0 \mathrm{Aa}$ & $0 \mathrm{Aa}$ & $0 \mathrm{Aa}$ & 0 Aa \\
\hline T12-Sem tratamento & $2,4 \mathrm{Bb}$ & $1,6 \mathrm{Ba}$ & $1,6 \mathrm{Ba}$ & $1,6 \mathrm{Ba}$ & $1,6 \mathrm{Ba}$ & $14,4 \mathrm{Cb}$ & $5,6 \mathrm{Ba}$ & $17,6 \mathrm{Cb}$ \\
\hline C.V. $(\%)$ & \multicolumn{2}{|c|}{29,3} & \multicolumn{2}{|c|}{30,2} & \multicolumn{2}{|c|}{25,1} & \multicolumn{2}{|c|}{33,8} \\
\hline
\end{tabular}

Médias seguidas pela mesma letra maiúscula nas colunas e minúscula nas linhas não diferem significativamente entre si (Tukey, 5\%). 
TABELA 8. Germinação (\%), primeira contagem de germinação (\%) e envelhecimento acelerado (\%) dos lotes 1 e 2 do cultivar de tomate UC-82, após tratamento térmico no experimento II.

\begin{tabular}{|c|c|c|c|c|c|c|}
\hline \multirow{2}{*}{ Tratamento térmico } & \multicolumn{2}{|c|}{ Germinação } & \multicolumn{2}{|c|}{ Primeira contagem } & \multicolumn{2}{|c|}{ Envelhecimento acelerado } \\
\hline & Lote 1 & Lote 2 & Lote 1 & Lote 2 & Lote 1 & Lote 2 \\
\hline $\mathrm{T} 7-55^{\circ} \mathrm{C} / 30 \mathrm{~min}$. & $89 \mathrm{Aa}$ & $89 \mathrm{ABa}$ & $53 \mathrm{Aa}$ & $51 \mathrm{Aa}$ & $61 \mathrm{Aa}$ & $63 \mathrm{Aa}$ \\
\hline $\mathrm{T} 10-60^{\circ} \mathrm{C} / 60 \mathrm{~min}$. & $0 \mathrm{Ba}$ & $0 \mathrm{Ba}$ & $0 \mathrm{Ca}$ & $0 \mathrm{Ca}$ & $0 \mathrm{Ca}$ & $0 \mathrm{Ca}$ \\
\hline T11-Fungicida & $85 \mathrm{Aa}$ & $83 \mathrm{Aa}$ & $18 \mathrm{Ba}$ & $21 \mathrm{Ba}$ & $35 \mathrm{Ba}$ & $35 \mathrm{Ba}$ \\
\hline T12-Sem tratamento & $87 \mathrm{Aa}$ & $93 \mathrm{Aa}$ & $59 \mathrm{Aa}$ & $59 \mathrm{Aa}$ & $54 \mathrm{Aa}$ & $59 \mathrm{Aa}$ \\
\hline C.V. $(\%)$ & \multicolumn{2}{|c|}{1,8} & \multicolumn{2}{|c|}{4,1} & \multicolumn{2}{|c|}{3,6} \\
\hline
\end{tabular}

Médias seguidas pela mesma letra maiúscula nas colunas e minúscula nas linhas não diferem significativamente entre si (Tukey, $5 \%$ ).

No experimento II, o grau de umidade das sementes de ambos os lotes, 1 e 2, variou de 7,4 a $9,3 \%$ e 9,0 a $10,1 \%$ antes dos testes de vigor e após o teste de envelhecimento acelerado, respectivamente, mantendo-se inferior ao limite recomendado.

\section{CONCLUSÕES}

O tratamento térmico (água quente a $55{ }^{\circ} \mathrm{C}$ por 30 min.) é uma opção consistente para o controle dos fungos Rhyzopus sp., Aspergillus sp. e Cladosporium sp. associados às sementes de tomate, sem prejudicar o potencial fisiológico das sementes.

Os tratamentos com água quente variando de 52 a 54 ${ }^{\circ} \mathrm{C}$ por 30 ou $60 \mathrm{~min}$. não causam prejuízo ao potencial fisiológico de sementes de tomate.

Os tratamentos a $60{ }^{\circ} \mathrm{C}$ por 30 ou 60 min. são eficientes para o controle de fungos, mas letais às sementes de tomate.

\section{REFERÊNCIAS}

BRASIL. Ministério da Agricultura e Reforma Agrária. Secretaria Nacional de Defesa Agropecuária. Departamento Nacional de Produção Vegetal. Coordenação de Laboratório Vegetal. Regras para análises de sementes. Brasília, DF, 1992. 365p.

COUTINHO, W.M., SILVA-MANN, R.; VIEIRA, M.G.G.C., MACHADO, C.F.; MACHADO, J.C. Qualidade sanitária e fisiológica de sementes de milho submetidas à termoterapia e condicionamento fisiológico. Fitopatologia Brasileira, v.32, n.6, p.458-464, 2007.

CUNHA, M.M.; REIFSCHNEIDER, F.J.B.; DELLA VECCHIA, P.T. Aspectos fitossanitários na produção de sementes de cenoura. Horticultura Brasileira, v.5, n.2, p.11-14, 1987.
GRONDEAU, C.; SAMSON, R. A review of thermotherapy to free plant materials from pathogens, especially seeds from bacteria. Critical Reviews in Plant Sciences, v.13, n.1, p.57-75, 1994.

IKUTA, J. Tratamento térmico de sementes e de tecidos de tomateiros (Lycopersicon esculentum Mill.) infectados por Clavibacter michiganense subsp michiganense (Smith) Davis et al e efeito de diferentes temperaturas sobre a bactéria cultivada “in vitro". 1990. 109f. Dissertação (Mestrado em Agronomia) - Faculdade de Ciências Agronômicas, Universidade Estadual Paulista "Júlio de Mesquita Filho", Botucatu, 1990.

LUCCA FILHO, O.A. Metodologia dos testes de sanidade de sementes. In: SOAVE, J.; WETZEL, M.M.V.S. (Ed.). Patologia de sementes. Campinas: Fundação Cargill, 1987. p.276-298.

MACHADO, J.C. Tratamento de sementes no controle de doenças. Lavras: LAPS; UFLA, FAEPE, 2000. 138p.

MAGUIRE, J.D. Speed of germination-aid in relation evaluation for seedling emergence vigor. Crop Science, v.2, n.2, p.176-177, 1962.

MARCOS FILHO, J. Fisiologia de sementes de plantas cultivadas. Piracicaba: FEALQ, 2005. 495p.

McMILLAN Jr, R.T. Preplant seed treatment of tomato for control of Xanthomonas campestris (pamm.) Dows. Pv. Vesicatoria (doidge) dye. Acta Horticulturae, Wageningen, $\mathrm{n}$. 198, p.53-58, 1987. Disponível em: <http://www.actahort. org/books/198/198_6.htm>. Acesso em: 10 jan. 2009.

MENDES, M.A.S.; LIMA, P.M.M.; FONSECA, J.N.L.; SANTOS, M.F. Erradicação de Fusarium oxysporum em sementes de alfafa utilizando termo e quimioterapia. Fitopatologia Brasileira, v.26, n.2, p.148-152, 2001. 
MUNIZ, M.F.B. Control of microganisms associated with tomato seeds using thermotherapy. Revista Brasileira de Sementes, v.23 n.1, p.176-280, 2001.

NEEGAARD, P. Seed pathology. London: The Mac Millan Press, 1979. v.2, 1191p.

PANOBIANCO, M.; MARCOS FILHO, J. Evaluation of the physiological potential of tomato seeds. Seed Technology, v.23, n.2, p.151-161, 2001.

RAHMAN, M.M.E.; ALI, M.E.; ALI, M.S.; RAHMAN, M.M.; ISLAM, M.N. Hot water thermal treatment for controlling seed-borne mycoflora of Maize. International Journal of Sustainable Crop Production, v.3, n.5, p.5-9, 2008. 